colloquia at University College, London, and at the Max Planck Institut für Physik, Göttingen; and to thank them and Prof. K. H. Bonhoeffer for valuable discussions on this topic.

${ }^{1}$ Simon, F., Nature, 133, 529 (1934).

${ }^{2}$ Simon, F., Ruhemann, M., and Edwards, W. A. M., Z. phys. Chem. B, 2, 340 (1929); 6, 62 (1929).

' Keesom, W. H., Leiden Comm., 184b (1926). Simon, F., and Swerson, C. A. (private communication).

- Compare Schottky, W., Naturwiss., 31, 400 (1943).

${ }^{5}$ See Prof. Schottky in the opening paragraph of ref. 4.

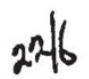

\section{EDUCATION IN PANAMA}

TO promote understand phg of educational conditions in the Amer, countries and 10 encourage co-operation in the field of inter-American education, the Unilof States Office of Education has undertaken the premation of a series of basic studies on educatidn in a number of Central South American countries under the sponsorship of an interdepart. natal committee on cultural and scientific coopefation. Each project involves travel by Office of Education specialists in the various countries in order to gather data on their educational sysiems at first hand and, afterwards, to prepare reports for publication.

Two of these reports dealing with education in Guatemala and Haiti have already been published and are now followed by an account of education in Panama which has been prepared by Delia Goetz*. Goetz divides her report into sections dealing with the land and the people, kindergarten and elementary education, secondary education, vocational education, teachers and teacher training, National Univer. sity of Panama, and general culture.

The history of Panama has been repeatedly influenced by its geographical position as the gateway to the Americas, culminating in the building of the canal by the United States at the beginning of this century. To it have come peoples of all kinds, including Caucasians, Mongolians, Africans, Europeans, Americans, Indians and Asiatics, with Spaniards dominating and leaving their mark on the speech of the country. Yet although Panama is a Spanishspeaking country, many parts of the country are inhabited entirely by English-speaking Jamaicans and West Indians, possessing their own churches and schools.

Panama is roughly the size of England and contains much mountainous, densely forested country, a vast expanse of which is tropical jungle. There are approximately 800,000 inhabitants, many of whom live near the Panama Canal or the Panama Railroad. Panama is essentially a rural country, however, and approximately half the population are engaged in agriculture, dairying, fishing and cattle raising. The agricultural methods are primitive, and although Panama's fertile soil and varied climate could produce a variety of crops, much of the basic food such c.s rice, potatoes, sugar, flour, fish, butter, eggs and tinned meat is imported.

Against this background, and an undeveloped public health system and an inadequate transport system, the state of education in Panama can be considered. In 1946 the Minister of Education reported that of a potential elementary school population of 120,000 only 82,807 were enrolled.

* Education in Panama. (U.S. Govt. Printing Office, 1948.)
Many of these live either in communities where their number is not large enough to warrant the establishment of a school or in places too distant from the nearest school. A survey of the living conditions of the school children showed that $56 \cdot 6$ per cent of the families lived in one room, 48.6 per cent of the houses lacked the most elementary sanitary arrangements and most of them had neither light nor ventilation.

Before the establishment of the Republic of Panama in 1903 the few educational facilities in Panama had been developed by the churches. During its forty-five years as an independent republic, considerable progress has been made in public education, and in the last few years the tempo of development has been remarkably quickened. The control of education in Panama is centralized in the office of the President of the Republic, whose Minister of Education has charge of nearly all official education in Panama. The Minister works through municipal boards on which teachers and parents are repre. sented; but, as there is no permanent professional staff at the Ministry of Education, a change of administration may bring in a new Minister who ignores or discards former plans or programmes of the municipal board. One-fifth of Panama's total budget is devoted to education; but the amount is quite inadequate to the needs. There is a great shortage of schools and equipment and many of the existing ones even in the large cities are housed in buildings which had been used as homes, stores or office buildings. When plans projected in 1946 for building are carried out-3,000,000 balboas were allocated for the construction of school buildingsmuch of this distressing shortage will be relieved.

In the different grades of education the story is also one of lack of suitable buildings, equipment, materials and teachers. The latter are often untrained, with the result that the kind of educational work being done is generally not in keeping with current educational theory. In the kindergartens, for example, the programme is usually formal, with little opportunity for creative work or free expression. In the primary schools one-third of the potential school population are never enrolled; while, in the rural areas, the majority of pupils drop out with half their schooling still to do. Although poverty of the parents and difficult communications in some areas account for this, it is significant that many children leave because the school fails to adapt itself to their needs and the needs of society in which they live.

Since Panama has few publishing firms, it is not surprising that text-books, particularly for element ary schools, are scarce. In the secondary schools shortages are also predominant, and this may account for the general lack of enthusiasm for sports and hobbies, but considerable interest in politics. Until recently, the student's curriculum was heavy with too many compulsory subjects; but in 1946 this was lightened and for the first time provision was made for optional subjects.

Vocational education in Fanama has made little headway because, as in other Latin American countries, there is considerable prejudice against working with one's hands. This is gradually passing, and in 1946 a three-year co-operative education programme in vocational education was inaugurated by the representatives of the United States Government and the Government of Panama. At present two or three schools throughout the country are providing good courses in technical education. 
The lack of trained teachers in Panama is mainly one of salaries, although the problem of finding teachers for rural areas is similar to that in all countries with large urbanized districts. At present primary school teachers are trained in an up-to-date normal school; but there is little facility for training secondary school teachers. Many secondary school teachers have been employed on a part-time basis, but a 1946 law provides for full-time secondary teachers who must be registered.

The National University of Panama was opened in 1935 and by 1946 had 467 men students and 288 women. Its faculties are grouped as: Philosophy and Letters and Education, Law and Political Sciences, Public Administration and Commerce, Sciences, Medical Sciences, Engineering and Architecture, while government is by a General University Council, an Administrative Board and the Board of Trustees, an interesting feature being that student representatives sit on all three governing bodies. No tuition fees are charged to students, while all classes are held in the late afternoon and evening, the university buildings being used for other educational purposes during the rest of the day.

General cultural activities in Panama are represented by a national and forty-three branch libraries, a national conservatory of music and speech, a symphony orchestra, national school of painting, national theatre and national museum and monuments.

T. H. HAWkins

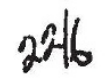

\section{ASTRONOMICAL NAVIGATION IN THE AIR}

A DISCUSSION of Prethods to produce speed 1 and accuracy in the practice of astronomical of was organised by the Institute of Navigation, ad held on June 17 in the lecture hall of the Rofal Geographical Society, under the chairmans 19 of the astronomer royal, Sir Harold Spfnct. Jones. In his introductory remarks Sir Hard directed attention to the fact that it was in the same hall, some twelve years earlier, that the Air Almanac had been first discussed in public.

The discussion was opened by Squadron Leader D. O. Fraser, who read a paper by Mr. J. B. Parker analysing the broad requirements of aids to air navigation. It is clear that 'astro' cannot fulfil the requirements of a universal aid for such specialized problems as homing and maintenance of traffic patterns ; since some such aid is necessary, a moderate accuracy (say a 95 per cent error of 10 nautical miles) will suffice for 'astro'. Mr. Parker then went on to advocate a simplification of the Air Almanac and reduction tables comparable to the modified require. ments.

Mr. A. H. Jessell proceeded to discuss the general problems arising in high-speed flight and the sort of sextant suitable for rapid fixing in pressure-cabin aircraft. He suggested the possibility of some form of automatic astro-compass for pilot use and improvements in optical systems so as to make star observations possible in day-time. This would then enable star curves to be used both by night and day; printed on a small scale, appropriate to the actual accuracy obtainable in the air, these would allow the sky to be mapped in a relatively small number of sheets.
Mr. D. H. Sadler briefly surveyed the various stages between observation and fix, and summarized existing methods. The astrograph (compare the suggested star curves) is the ideal instrument in principle, but cannot be readily applied to the sun, moon or planets. He therefore examined the possibility of (1) an altitude-azimuth almanac and (2) an almanac tabulating Aquino's $a$ and $b$; even with special methods of non-linear interpolation, long intercepts and the reduced accuracy (about $5^{\prime}$ ) comparable with Parker's requirements, neither almanac offers any substantial advantage over the existing methods.

Then, a position line protractor for use with long intercepts was described by Mr. P. F. Everitt. Constructed on a stereographic projection to a scale of $1: 3$ million, it can be used to draw curved position lines on both the stereographic and, without appreciable error, the Lambert conformal projections. The use of such an instrument would enable considerable reduction to be made in the size of altitude-azimuth tables. He also suggested the precomputation of altitudes and azimuths by a ground staff before flight, with the navigator applying corrections for run and difference in time.

M. A. J. Bastien, who had made a special visit from France to take part in the discussion, read an interesting paper by his colleague, M. R. Genty, describing a method for solving the astronomical spherical triangle when the altitude and azimuth are both observed. A sextant for the simultaneous observation of these quantities (using Polaris or $\beta$ Hydri as reference for azimuth) has been made and gives promising results on the ground. A fix is ibtained simply by means of special tables.

The practicability of a system, first suggested by Captain Brett Hilder, for locating the zenith among the stars by photography was then discussed by Dr. R. d'E. Atkinson. He showed that it would be possible to determine a position simply and quickly by positioning the developed plate on suitable star charts. For the first time in the discussion he raised the unsolved problem of the definition of the vertical and suggested a method for the suspension of the camera, using a form of lazy-tongs linkage connecting two equal gyroscopes, as originally suggested by Mr. F. J. Hargreaves.

M. Bastien described in some detail the basic principles of an instrument which would record instant. aneously and continuously the latitude and longitude of an aircraft during flight, as deduced from stellar observations. The difficulties lie, however, in the practical details of the construction and operation, and it cannot be anticipated that such an instrument, giving a continuous geometrical solution, will be generally available in the near future.

A view, opposed to many of the previous speakers, was taken by Mr. Francis Chichester, who argued that a relatively high order of accuracy will be required from astronomical navigation to determine wind effect. He concluded that the principal failing at present is in the lack of a vertical datum and that, until a far more accurate solution of this problem has been established, it is a waste of effort to improve the other elements of the operation.

At the conclusion of these eight prepared papers, the chairman opened the meeting to general discussion. Captain R. C. Alabaster, in the course of comments on each of the papers, was quite definite that a lesser degree of accuracy cannot be accepted, and that an overall reduction in the time necessary 